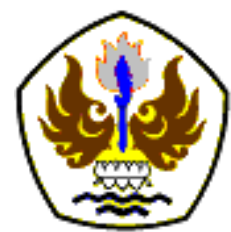

INFOMATEK

Volume 21 Nomor 1 Juni 2019

\title{
PERANCANGAN KNOWLEDGE MANAGEMENT SYSTEM PADA TENAGA KEPENDIDIKAN DI PERGURUAN TINGGI
}

\author{
Fahmi Aldi Choirunsyah), Hery Heryanto \\ Program Studi Pascasarjana Magister Sistem Informasi \\ Fakultas Pascasarjana - STMIK LIKMI
}

\begin{abstract}
Abstrak: Universitas Pasundan merupakan salah satu Perguruan Tinggi Swasta terkemuka yang ada di Jawa Barat. Sebagai universitas yang terus melakukan perbaikan dalam kinerjanya, Universitas Pasundan harus dapat menjawab tantangan zaman dari mulai peningkatan infrastruktur, kinerja dosen, sampai kepada tenaga kependidikan sebagai ujung tombak pelayanan yang dilakukan kepada mahasiswa, dosen dan sesama karyawan. Tenaga kependidikan dituntut dengan cepat beradaptasi dan belajar mengenai kemampuan teknis dalam berbagai bidang yang ada dilingkungan Universitas. Untuk mengatasi masalah unversitas secara keseluruhan, mulai dari tuntutan adaptasi terhadap pekerjaan yang ada sehingga terbentuk proses pelayanan yang baik dan cepat, perlu adanya suatu sistem yang dapat mengelola dan mendistribusikan pengetahuan kepada karyawan agar pengetahuan yang ada pada karyawan senior (pakar) dapat dimiliki oleh karyawan yang baru serta meminimalisir terjadinya kesalahan dalam pekerjaan yang selalu berulang. Penelitian ini berfokus kepada Perancangan Sistem Manajemen Pengetahuan (Knowledge Management System) untuk tenaga kependidikan di perguruan tinggi studi kasus pada Universitas Pasundan dalam upaya menjawab tantangan jaman dan keunggulan bersaing. Penelitian ini menggunakan Work System Framework, Knowledge Taxonomies, dan 6 Langkah dari The 10-Step Knowledge Management Roadmap. Hasil akhir adalah blueprint berupa prototype KMS untuk mengelola KM di Universitas Pasundan.
\end{abstract}

Kata kunci: Business Process, Work System Framework (WSF), 10-Step Knowledge Management Roadmap, Tenaga Kependidikan, Pendidikan Tinggi

\section{PENDAHULUAN}

Universitas Pasundan merupakan salah satu

Perguruan Tinggi Swasta terkemuka yang ada

di Jawa Barat. Sebagai universitas yang terus

melakukan perbaikan dalam kinerjanya,

Universitas Pasundan harus dapat menjawab

tantangan zaman dari mulai peningkatan

infrastruktur, kinerja dosen, sampai kepada

*) fahmi.aldi@unpas.ac.id

Pertama diterima : 30 April 2019

Direvisi :16 Mei 2019

Disetujui untuk publikasi:31 Mei 2019 tenaga kependidikan sebagai ujung tombak pelayanan yang dilakukan kepada mahasiswa, dosen dan sesama karyawan.

Dari data dalam tiga tahun terakhir yang diperoleh pada laman SDM Universitas Pasundan (http://sdm.unpas.ac.id [1]), terdapat peningkatan jumlah tenaga kependidikan di antaranya jumlah tenaga tetap, kontrak dan aktivitas perekrutan seperti pada Gambar 1. 




Gambar 1.

Tren Peningkatan Data Tenaga Kependidikan dalam Tiga Tahun Terakhir [1]

Gambar 1 menunjukan tren peningkatan jumlah tenaga kependidikan yang dapat menimbulkan konsekuensi berupa aktivitas mutasi, rotasi, pensiun dan kenaikan jabatan pada tenaga kependidikan yang ada di universitas seperti dijelaskan pada Gambar 2.

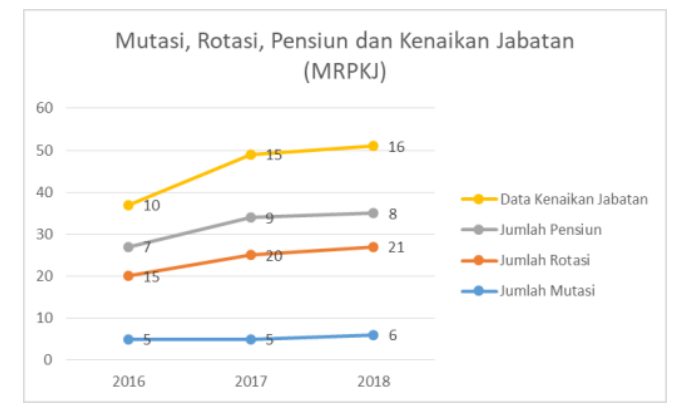

Gambar 2.

Tingkat MRPKJ Tenaga Kependidikan dalam Tiga Tahun Terakhir [1]

Dari aktivitas yang telah dijelaskan dalam Gambar 2 terdapat masalah baru dalam organisasi yaitu kehilangan tenaga kependidikan senior sebagai pakar pada kegiatan MRPKJ, tenaga kependidikan yang harus terus beradaptasi dengan cepat dalam kegiatan mutasi ke bagian lain dan rotasi pada fungsi yang lain, serta adaptasi penambahan beban kerja pada tenaga kependidikan yang naik jabatan. Kemudian terjadi juga beban kerja individu yang terus meningkat setiap tahunnya dari mulai 1 tenaga kependidikan yang betanggungjawab terhadap 271 task dalam setahunnya sampai melonjak 1 tenaga kependidikan yang betanggungjawab terhadap 825 task per tahun pada tahun 2018 seperti yang dijelaskan pada Gambar 3.

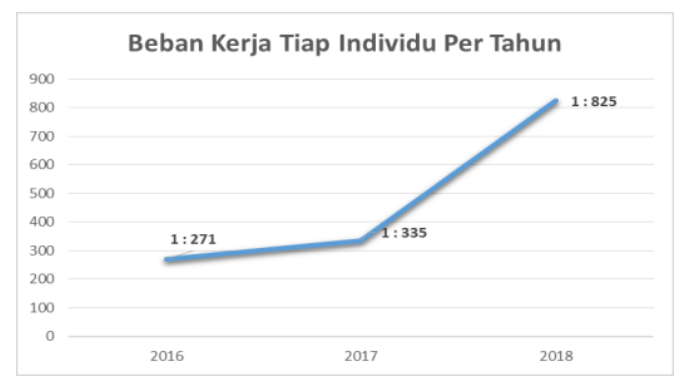

Gambar 3.

Beban Kerja Per Individu Per Tahun [1]

Dari Gambar 1, 2 dan 3 menjelaskan tren peningkatan beban individu dari setiap tenaga kependidikan dalam tiga tahun terakhir. Tenaga kependidikan dituntut dengan cepat beradaptasi dan belajar mengenai kemampuan teknis dalam berbagai bidang yang ada di lingkungan universitas.

Untuk mengatasi masalah unversitas secara keseluruhan, mulai dari tuntutan adaptasi terhadap pekerjaan yang ada sehingga 
terbentuk proses pelayanan yang baik dan cepat, perlu adanya suatu sistem yang dapat mengelola dan mendistribusikan pengetahuan kepada karyawan agar pengetahuan yang ada pada karyawan senior (pakar) dapat dimiliki oleh karyawan yang baru serta meminimalisir terjadinya kesalahan dalam pekerjaan yang selalu berulang. Penelitian ini berfokus kepada Perancangan Sistem Manajemen Pengetahuan (Knowledge Management System) untuk tenaga kependidikan di perguruan tinggi studi kasus pada Universitas Pasundan dalam upaya menjawab tantangan jaman dan keunggulan bersaing.

\section{METODOLOGI}

Metodologi Penelitian adalah cara sistematis untuk memecahkan masalah. Metodologi Penelitian merupakan ilmu yang mempelajari bagaimana penelitian harus dilakukan. Dari mulai prosedur di mana para peneliti harus melakukan penelitiannya menggambarkan, menjelaskan dan memprediksi fenomena yang terjadi. Metodologi Penelitian juga didefinisikan sebagai studi tentang cara dimana pengetahuan diperoleh. Tujuannya adalah untuk memberikan rencana kerja penelitian.

Gambar 4 akan menjelaskan tahapan-tahapan yang dilalui selama pelaksanaan penelitian menggunakan bebagai cara yang diambil berdasarkan beberapa referensi.

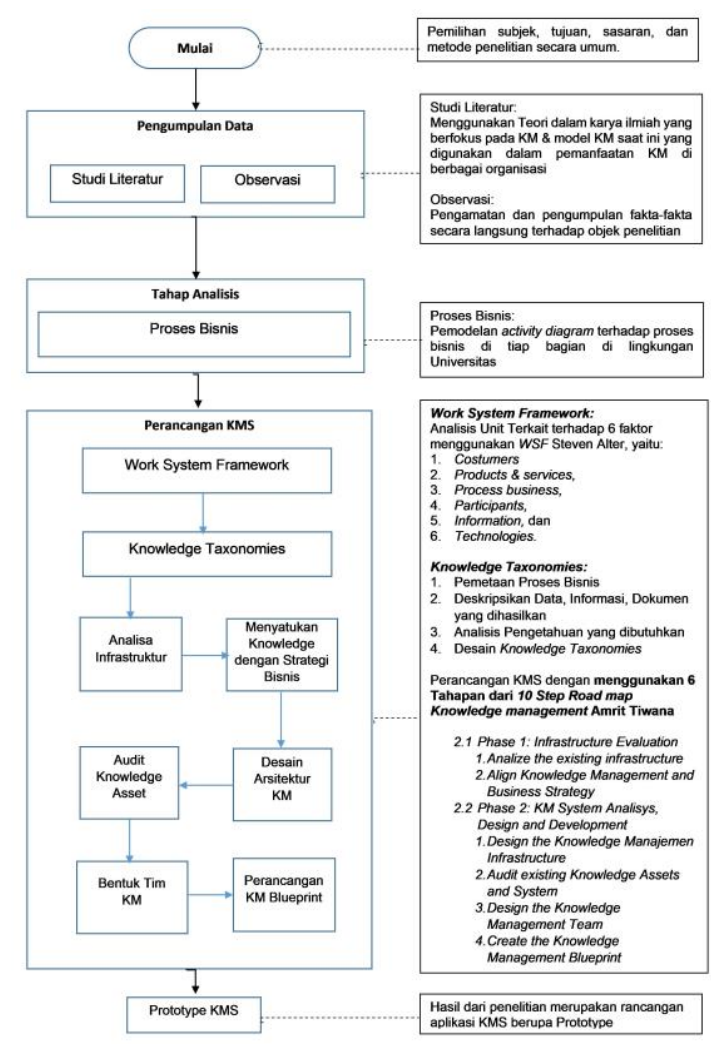

Gambar 4.

Tahapan penelitian Hipotesis

Penelitian ini ditujukan untuk Mengidentifikasi pengetahuan yang ada dalam Organisasi untuk di kelola dan dimanfaatkan oleh tenaga kependidikan agar dapat meningkatkan keunggulan bersaing.

\subsection{Knowledge Management System (KMS)} Knowledge Management System (KMS) adalah suatu alat yang bertujuan mendukung manajemen pengetahuan, dan merupakan pengembangan dari alat manajemen informasi yang mengintegrasikan berbagai aspek ilmu 
komputer dalam mendukung kolaborasi antara lingkungan kerja dengan informasi dan sistem pengelolaan dokumen. Hal ini sesuai dengan yang diungkapkan oleh Kimiz Dalkir: Knowledge management systems (KMSs) are tools aimed at supporting knowledge management. They evolved from information management tools that integrated many aspects of computer-supported collaborative work (CSCW) environments with information and document management systems (Ganesan, Edmonds, and Spector, 2001; Greif, 1988; Kling, 1991 dalam Dalkir [2]).

\subsection{Knowledge Management Perguruan}

\section{Tinggi}

Di perguruan tinggi, pengelolaan berfokus pada 3 kelompok penting, yaitu pengelolaan atas proses (proces), isi (content), dan sumber daya (resources), seperti yang tergambar pada Gambar 5. Tentu saja di luar 3 kelompok tersebut, ada pengaruh akan organisasi dan budaya organisasi, nilai-nilai, ethos kerja, dan kepemimpinan. Masing-masing kelompok tidak dapat dikelola secara terpisah, namun terpadu dengan memperhatikan arah pengembangan perguruan tinggi masingmasing (visi, misi, tujuan dan sasaran). (Prabowo [3]).

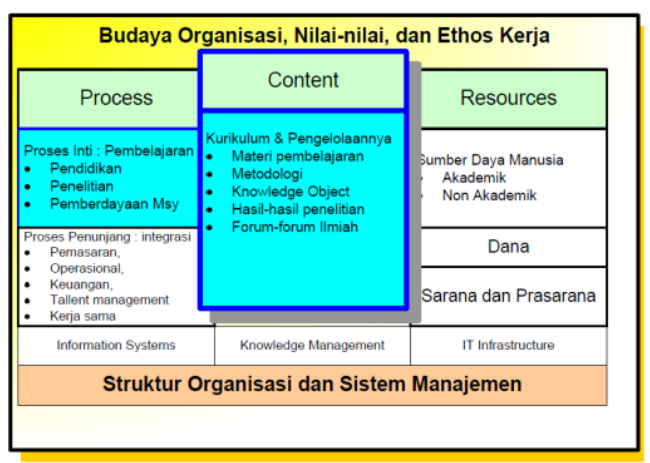

Gambar 5.

Pengelolaan perguruan tinggi [3]

\subsection{Work System Framework (WSF)}

Work System Framework merupakan sistem yang partisipan terdiri dari manusia atau mesin yang melaksanakan proses bisnis dengan menggunakan informasi, teknologi dan sumberdaya lain untuk menghasilkan suatu produk atau layanan untuk internal atau eksternal customer (Choirunsyah, dkk. [4]).

Sembilan elemen work system framework memberikan dasar untuk mendeskripsikan dan menganalisis sistem kerja yang bergantung pada teknologi informasi dalam sebuah organisasi. Kerangka kerja tersebut menguraikan komponen-komponen pada tampilan statis pada sistem kerja dimana detail kecil mungkin berubah secara bertahap dari waktu ke waktu, namun tanpa mengubah keseluruhan struktur, identitas, atau integritas sistem kerja. Pandangan semacam itu merangkum bentuk dan fungsi sistem kerja pada suatu titik waktu dan dirancang untuk menekankan bisnis daripada masalah 
teknologi informasi. Ini mencakup situasi yang memilki atau mungkin tidak memiliki proses bisnis yang ketat atau tidak terlalu intensif. (Alter [5]).

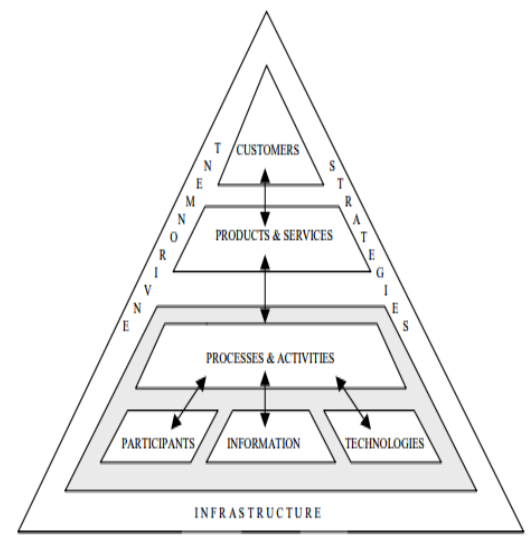

Gambar 6.

The work system framework [5]

Gambar 6 secara inheren berorientasi pada layanan karena ia mengatakan bahwa sistem kerja ada untuk menghasilkan produk dan layanan bagi pelanggan. Anak panah mengatakan bahwa unsur-unsur sistem kerja harus sejajar

\subsection{Knowledge Taxonomies}

Taksonomi adalah sistem klasifikasi dasar yang menggambarkan konsep dan ketergantungannya, biasanya digambarkan secara hirarkis. Semakin tinggi konsep yang ditempatkan, semakin umum atau generik konsepnya. Konsep yang lebih rendah ditempatkan, merupakan kategori tingkat tinggi yang lebih spesifik. Taksonomi paling berguna dalam organisasi pengetahuan deklaratif seperti yang diwujudkan oleh sistem diagnostik. Pembangunan taksonomi melibatkan mengidentifikasi, mendefinisikan, membandingkan, dan mengelompokkan elemen kedalam bentuk hirarki.

Knowledge Taxonomies memungkinkan pengetahuan diwakili secara grafis sedemikian rupa sehingga mencerminkan pengorganisasian konsep dala bidang keahlian tertentu atau untuk organisasi pada umumnya. Contoh ditunjukkan pada Gambar 7 [2].

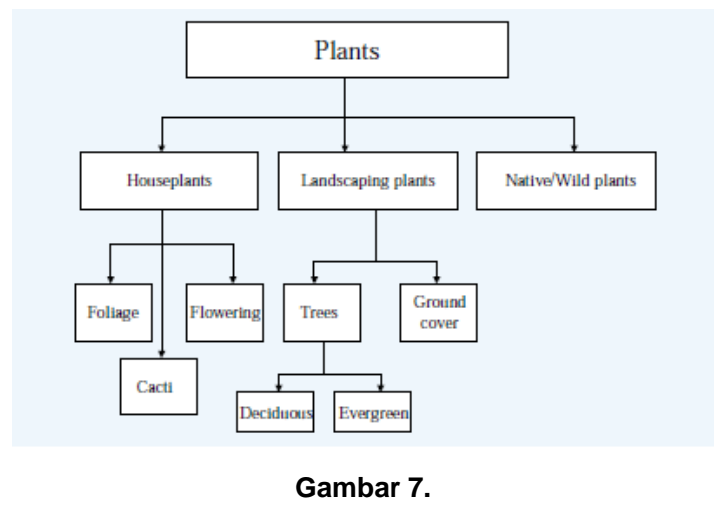

Contoh knowledge taxonomies [2]

Seperti yang terlihat pada Gambar 5 yang menggambarkan mengenai Plants merupakan induk atau bagian dari Houseplants, Landscaping plants dan native/ Wild plants dan seterusnya. Plants menjadi akar yang tertinggi dan berbicara global, semakin kebawah maka akan semakin spesifik, teori mengenai Knowledge Taxonomies ini berguna dalam menggambarkan struktur organisasi 
dan pengetahuan serta menentukan pengetahuan yang global sampai kepada pengetahuan yang spesifik yang ada pada suatu organisasi.

\subsection{The 10-Step Knowledge Management Roadmap}

The 10-Step Knowledge management Roadmap ini membagi 4 fase dalam membangun Knowledge management, dan terdiri dari 10 langkah dalam keseluruhan fase. Gambar 8 menjelaskan 10 langkah dari ke 4 fase menurut Amrit Tiwana.

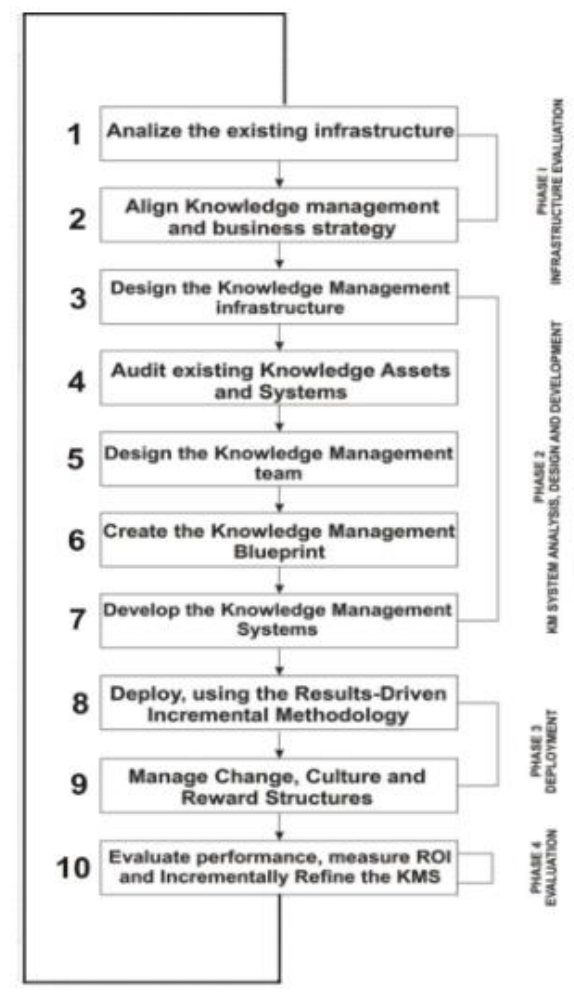

Gambar 8.

The 10 - step knowledge management roadmap (Tiwana [6])
Gambar 8 menjelaskan kembali dengan deskripsi-deskripsi di bawah ini:

1. Phase 1: Infrastructure Evaluation

Dalam fase Evaluasi Infrastruktur ini terdapat 2 langkah di dalamnya, yaitu Analyze the Existing Infrastructure, dan Align Knowledge management and Business Strategy.

2. Phase 2: KM System Analisys, Design and Development

Dalam fase Analisis Sistem Knowledge management, Desain dan Pengembangan ini terdapat 5 langkah didalamnya, yaitu: Design the Knowledge management Infrastructure, Audit Existing Knowledge Assets and Systems, Design the Knowledge management Team, Create the Knowledge management Blueprint, Develop the Knowledge management System.

a. Mendesain Infrastruktur Knowledge management

b. Mengaudit Aset dan sistem Knowledge yang Ada

c. Mendesain Tim Knowledge management

Tim knowledge management didesain dengan komposisi sebagai berikut:
1) Local expert dan inter- departemental gurus
2) Internal information technology expert
3) Non local expert dan extra- 
departemental gurus
4) Consultant
5) Senior manager

d. Menciptakan Blueprint Knowledge management

Pada tahap kelima, tim knowledge management mendesain sistem manajemen baru.

e. Pengembangan Knowledge management system

Pada tahap ini tim harus bekerja sekaligus menggabungkan knowledge management system yang sudah bangun pada tahap enam sebelumnya.

Konstruksi sistem mencakup tujuh lapis, yaitu sebagai berikut:

1) Interface layer

2) Access and authentication layer

3) Collaborative filtering and intelligence layer

4) Application layer

5) Transport layer

6) Middleware and legacy integration layer

7) Repositories

3. Phase 3: Deployment

Dalam fase Penyebaran, terdapat 2 langkah didalamnya, yaitu Deploy, Using the Results-driven Incremental Methodology, dan Manage Change, Culture and Rewards Structures a. Prototipe dan Uji Coba

b. Pengelola Perubahan, Kultur, dan Struktur Penghargaan

4. Phase 4: Evaluation

Pada fase terakhir adalah Evaluasi, dengan langkahnya berupa Evaluate Performance, Measure ROI, and Incrementally Refine the KMS. Untuk tujuan pengukuran hasil knowledge management, Tiwani menggunakan perspektif sebagai berikut:

a. Financial perspective (perspektif finansial)

b. Human-capital perspective (perspektif modal manusia)

c. Customer-capital perspective (perspektif modal pelanggan)

d. Organizational-capital perspective (perspektif modal organisasi)

\section{ANALISIS DAN PEMBAHASAN}

\subsection{Analisis Work System Framework pada} Tenaga Kependidikan

Work System Framework (WSF) menggambarkan Sistem kerja yang ada pada Tenaga Kependidikan. Sistem kerja dapat diidentifikasikan dengan memotret beberapa faktor seperti Customer, Product and Service, Business Process, Participant dan information. 


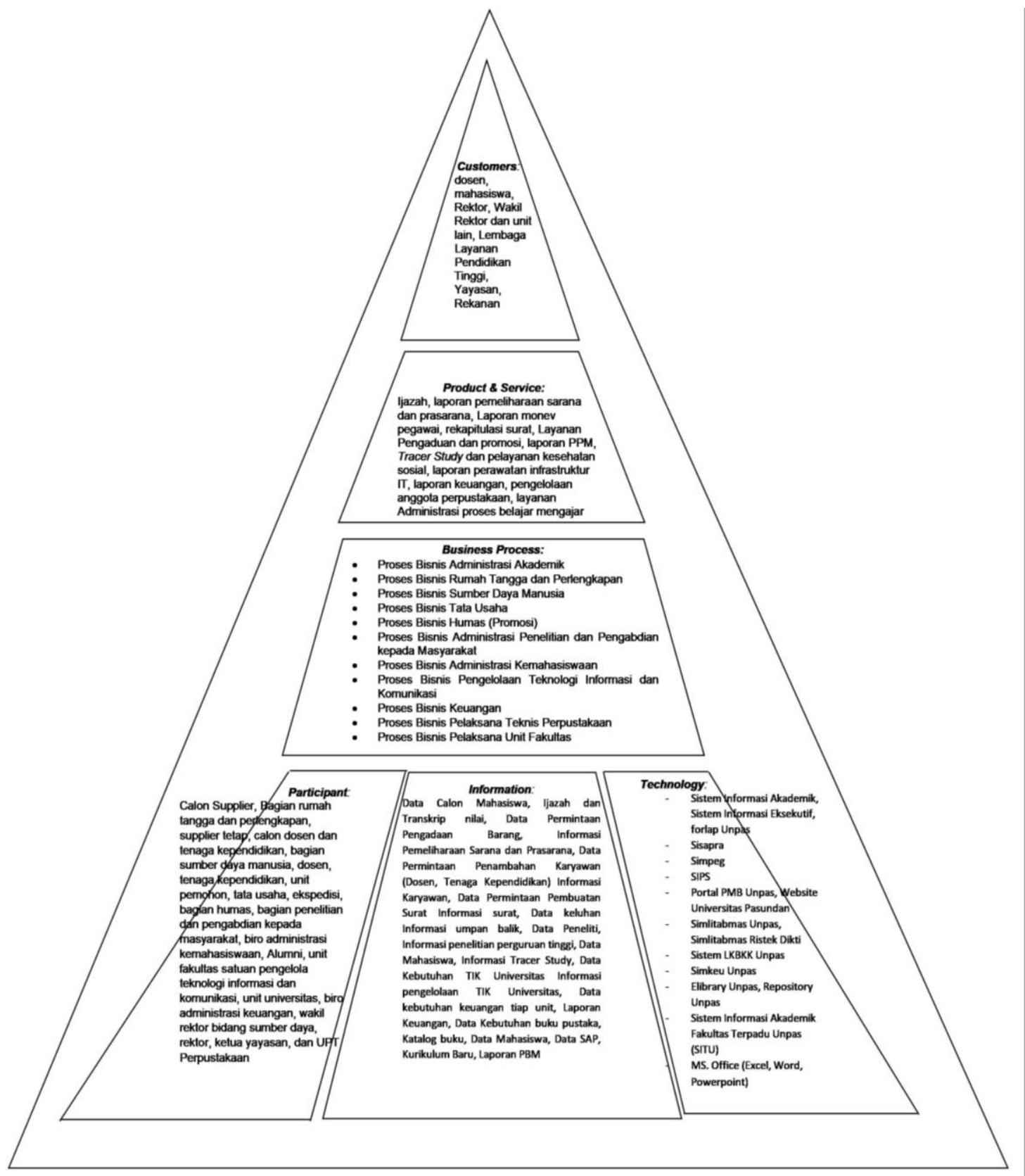

Gambar 9. Work system Framework (WSF)

\subsection{Knowledge Taxonomies}

Taksonomi pengetahuan dibutuhkan untuk melihat beberapa perbedaan dari berbagai jenis pengetahuan yang dibutuhkan dalam proses bisnis dan aktivitas yang ada pada Tenaga Pendidikan di Universitas Pasundan. 
Gambar 10 menjelaskan mengenai tahapan pengelompokan hirarki pengetahuan berdasarkan kebutuhan proses bisnis pada Tenaga Pendidikan di Universitas Pasundan.



Gambar 10.

Proses Desain Knowledge Taxonomies

\subsection{Desain Knowledge Taxonomies}

Setelah mendefinisikan pengetahuan yang dibutuhkan oleh tenaga kependidikan di Universitas Pasundan melalui Proses Bisnis, Work System Framework (WSF), dan pengetahuan berdasarkan deskripsi dari data, informasi, Dokumen dan Permasalahan yang muncul kemudian dapat dilakukan proses Desain Pengetahuan kedalam Knowledge Taxonomies. Dalam penelitian ini, pengetahuan dikelompokan berdasarkan tipetipe pengetahuan yaitu pengetahuan faktual, pengetahuan konseptual, pengetahuan prosedural dan pengetahuan metakognitif seperti yang dijelaskan pada Gambar 11.

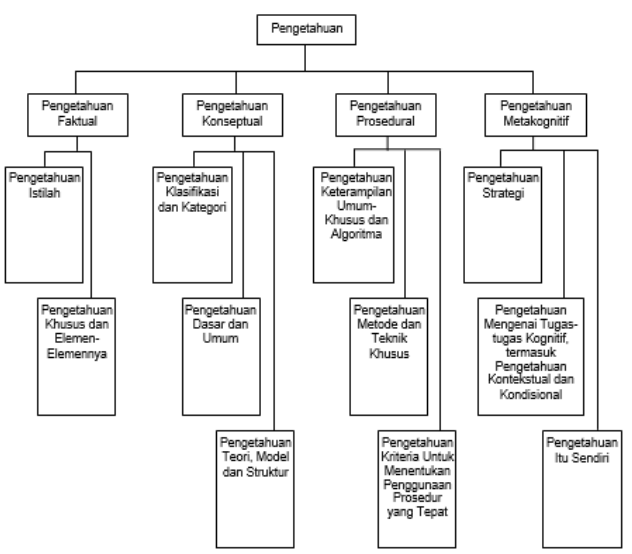

Gambar 11.

Knowledge taxonomies Tenaga Kependidikan

\subsection{Perancangan Knowledge Management System}

Knowledge Management System dirancang sebagai media untuk melakukan pengelolaan pengetahuan dari mulai proses penciptaan pengetahuan sampai pemanfaatan pengetahuan yang ada agar dapat mempercepat pertukaran pengetahuan di dalam organisasi.

Dalam penelitian ini bertujuan untuk menghasilkan suatu rancangan Knowledge Management System berupa blueprint sistem tersebut. Karena tujuan penelitian ini menghasilkan Blueprint KMS maka perancangan knowledge management system dilakukan melalui 2 tahap dari 4 Tahap road map knowledge management Amrit Tiwana 
tahap yaitu tahap evaluasi infrastruktur dan tahap analisis desain yang meliputi 6 langkah dalam 10 step road map knowledge management Amrit Tiwana. Untuk mempermudah memahami alur dari tahap Gambar 12.

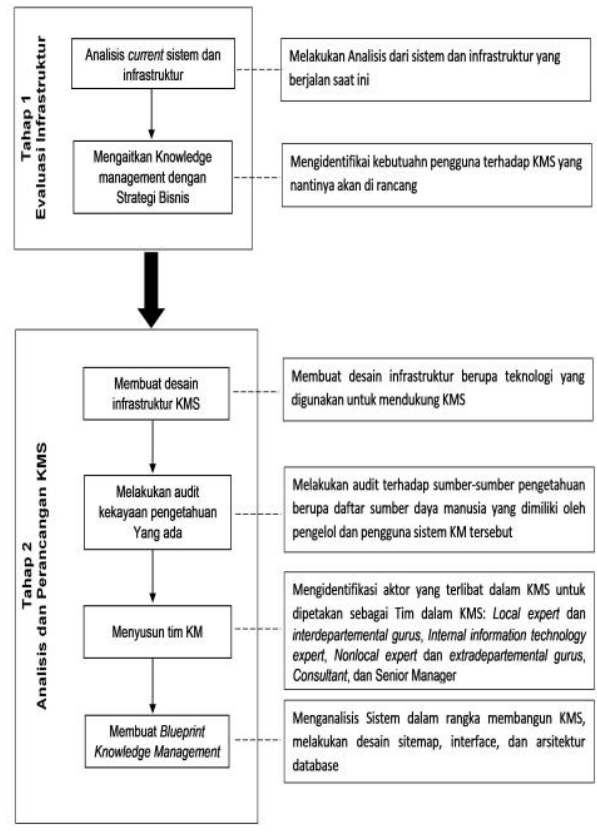

Gambar 12.

Tahapan perancangan KMS

\subsection{Analisis Sistem dan Infrastruktur Saat} ini

Analisis Infrastruktur dibutuhkan untuk meninjau seberapa baik infratruktur yang ada sekarang dan dapat mengevaluasi apakah sistem yang ada bisa ditingkatkan dengan menggunakan metode tertentu. Infrastruktur yang sangan dekat dengan pengguna adalah prangkar komputer dan jaringan serta sistem informasi yang ada di dalam sebuah unit bisnis tersebut. Gambar 13 memperlihatkan secara general bagaimana infrastruktur saat ini berperan dalam membantu tercapainya suatu tujuan proses bisnis.

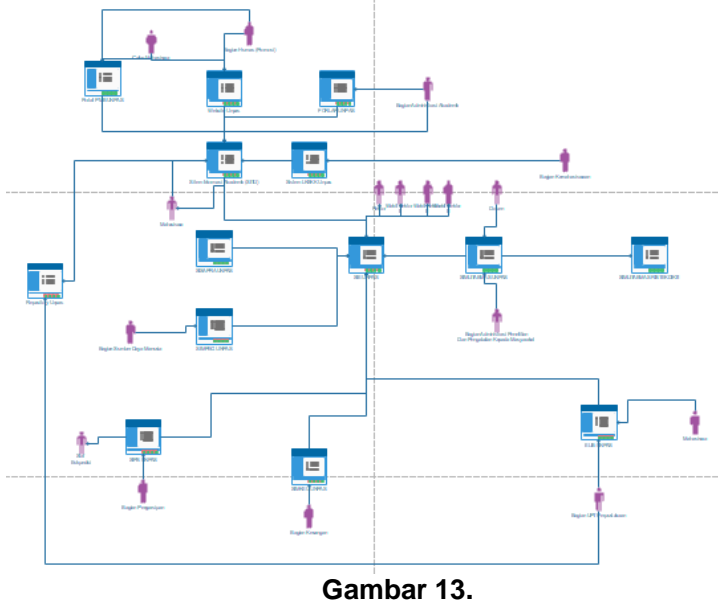

Sistem dan infrastruktur saat ini



Gambar 14.

Aktivitas Catat Reward 
1. Class diagram

(metode), dan hubungan antar objek dalam Class diagram KMS dibuat untuk KMS. Gambar 15 menjelaskan bagaimana menggambarkan struktur sistem dengan menunjukkan kelas sistem, atribut, operasi gambaran hubungan antar objek dalam KMS melalui class diagram

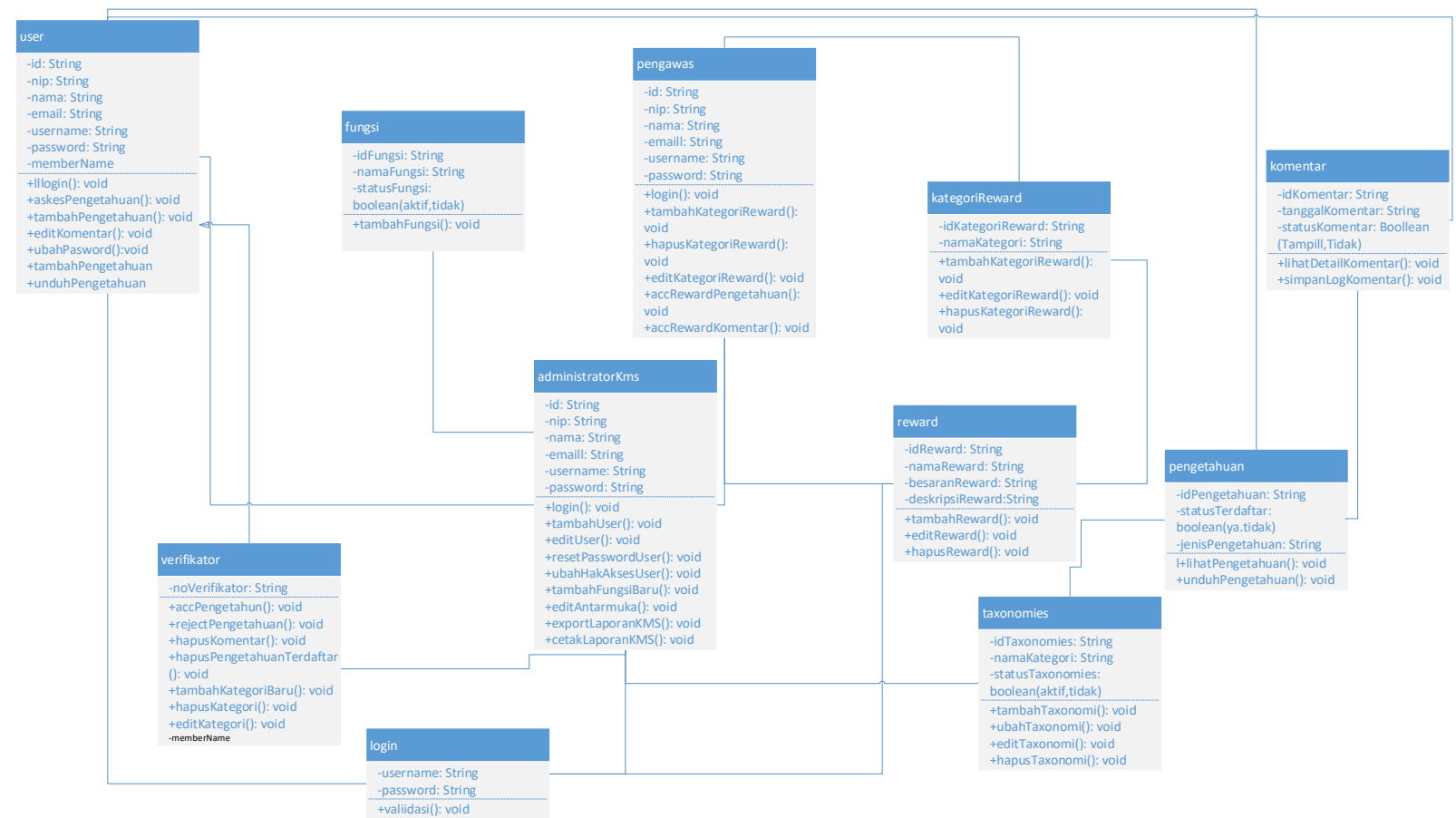

Gambar 15.

Class diagram KMS Tenaga Kependidikan di Universitas

\subsection{Blueprint KMS Tenaga secara utuh.}

\section{Kependidikan di Perguruan Tinggi}

1. Desain arsitektur KMS pada Tenaga Kependidikan di Perguruan Tinggi.

Desain arsitektur merupakan tahap awal dalam proses desain perangkat lunak, dibuat untuk menggambarkan bagaimana sistem ini disusun sebagai satu set komponen untuk berkomunikasi. Melalui desain arsitektur kita dapat mengetahui hubungan setiap komponen yang ada dalam sistem yang tergambar
Gambar 16 menjelaskan arsitektur KMS pada tenaga kependidikan di perguruan tinggi yang akan dibangun yang meliputi kebutuhan informasi, komponen sistem, dan teknologi pendukung.

2. Desain interface KMS pada Tenaga Kependidikan di Perguruan Tinggi

Dari Sitemap yang telah deskripsikan maka desain Interface KMS dibuat sebagai 
gambaran dan merepresentasikan sistem sesungguhnya secara utuh. Desain interface KMS pada tenaga kependidikan di perguruan tinggi dijadikan sebagai blueprint sistem KMS yang terdapat di universitas pasundan dengan objek yaitu tenaga kependikan. Gambar 17 menjelaskan mengenai Halaman login yang terdapat pada aplikasi Knowledge Management Information System Pasundan.



Gambar 16.

Arsitektur KMS pada Tenaga Kependidikan di Perguruan Tinggi 
ditunjukan pada Gambar 19.

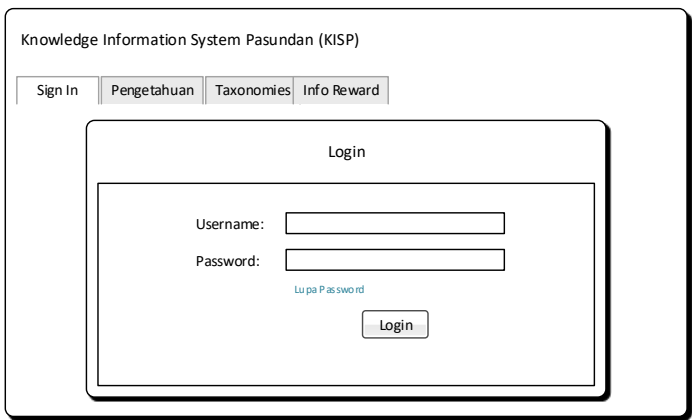

Gambar 17.

Halaman Login (autentikasi)

Setelah dideskripsikan mengenai halaman login pada aplikasi KMS pada tenaga pendidikan di perguruan tinggi, Gambar 18 menjelaskan mengenai proses pencarian pengetahuan oleh Hak Akses User.

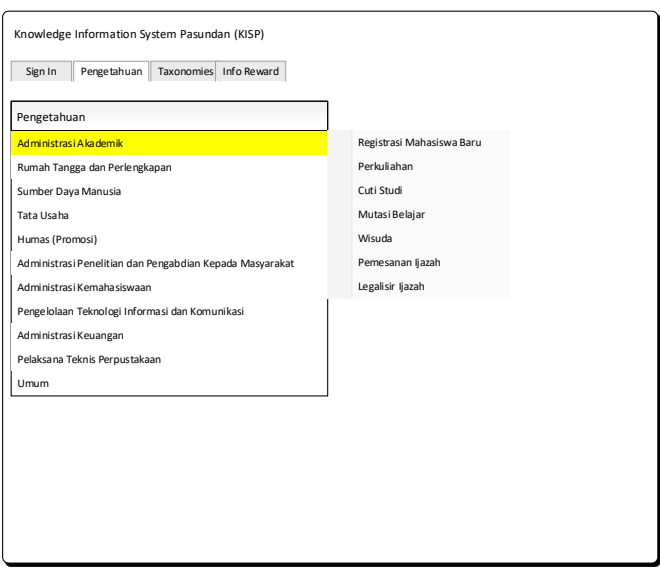

Gambar 18.

Halaman Mencari Pengetahuan

Aplikasi ini juga menggambarkan proses verifikasi kandidat pengetahuan yang akan dikirimkan pada halaman publik melalui proses verifikasi oleh verifikator akan

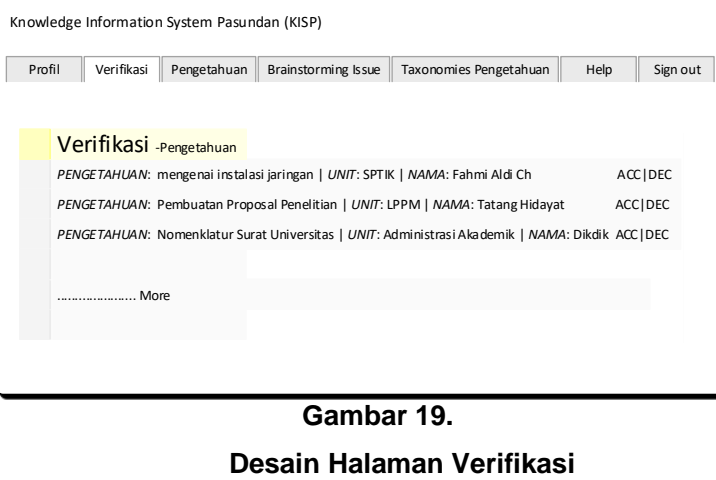

Gambar 19.

Desain Halaman Verifikasi

\section{KESIMPULAN}

Kesimpulan dan saran yang dapat diambil dari penelitian ini yaitu:

1. Tenaga Kependidikan merupakan peran yang sangat penting, karena dengan adanya tenaga kependidikan, Aktivitas Administratif yang kompleks dapat dengan mudah diatasi, untuk menvapai Visi dan Misi Universitas perlu adanya penyebaran pengetahuan yang merata diantara tenaga kependidikan yang ada di universitas.

2. Pembuatan Blueprint sebagai langkah baik dalam memulai arsitektur pengetahuan yang baik, menstimulasi para tenaga kependidikan untuk mengeluarkan tacit knowledge dan menjadikannya eksplisit dengan bantuan blueprint aplikasi KMS ini.

\section{DAFTAR PUSTAKA}

[1] http://sdm.unpas.ac.id/index.php/dashboard. 
Dashboard Eksekutif SDM 2018. Diakses 24 September 2018.

[2] Dalkir, K. Knowledge Management in Theory and Practice, USA: Elsevier Inc., 2005

[3] Prabowo, H. "Knowledge Management di Perguruan Tinggi," Binus Business Review vol.1 no.2, pp. 407-415, 2010.

[4] Choirunsyah, F. A., Lidya, L. "Studi Penerapan Knowledge Management Pada Pemberi Layanan Tingkat Pertama Sistem Jaminan Kesehatan Nasional”, Konferensi
Nasional Sistem Informasi 2016, pp. 425430, 2015.

[5] Alter, S. Information System: The Foundation of E-Businnes, USA: Prentice Hall, Fourth Edition, 2002.

[6] Tiwana, A. The Knowledge management Toolkit, New York: Prentice Hall PTR Upper Saddle River, 2000. 